\title{
Brief Chilling to Subzero Temperature Increases Cold Hardiness in the Hatchling Painted Turtle (Chrysemys picta)
}

\author{
Timothy J. Muir \\ Jon P. Costanzo \\ Richard E. Lee \\ Department of Zoology, Miami University, Oxford, Ohio \\ 45056
}

Accepted 3/22/2009; Electronically Published 11/30/2009

\begin{abstract}
Although many studies of ectothermic vertebrates have documented compensatory changes in cold hardiness associated with changes of season, much less attention has been paid to adjustment of physiological functions and survival limits following more acute exposure to cold. We investigated the ability of hatchling painted turtles (Chrysemys picta) to increase cold hardiness in response to brief exposure to a subzero temperature. Winter-acclimated turtles were "cold conditioned" by chilling them in the supercooled (unfrozen) state to $-7^{\circ} \mathrm{C}$ over a few days before returning them to $4^{\circ} \mathrm{C}$. These turtles fared no better than control animals in resisting freezing when cooled in the presence or absence of ice and exogenous ice nuclei. Survival following tests of freeze tolerance (freezing for about $70 \mathrm{~h}$; minimum body temperature, $-3.75^{\circ} \mathrm{C}$ ) was nominally higher in cold-conditioned turtles than in controls (36\% vs. $13 \%$, respectively), although the difference was not statistically significant. Of the survivors, cold-conditioned turtles apparently recovered sooner. Turtles subjected to cold shock (supercooling to $-13^{\circ} \mathrm{C}$ for $24 \mathrm{~h}$, followed by rewarming to $0^{\circ} \mathrm{C}$ ) were strongly affected by cold conditioning: all controls died, but $50 \%$ of cold-conditioned turtles survived. We investigated potential mechanisms underlying the response to cold conditioning by measuring changes in levels of putative cryoprotectants. Plasma levels of glucose and lactate, but not urea, were higher in cold-conditioned turtles than in controls, although the combined increase in these solutes was only $23 \mathrm{mmol} \mathrm{L}^{-1}$. Cold conditioning attenuated cold-shock injury to brain cells, as assessed using a vital-dye assay, suggesting a link between protection of the nervous system and cold hardiness at the organismal level.
\end{abstract}

${ }^{\star}$ Corresponding author. Present address: Biology Department, Augustana College, Rock Island, Illinois 61201; e-mail: timmuir@augustana.edu.

Physiological and Biochemical Zoology 83(1):174-181. 2010. (C) 2010 by The University of Chicago. All rights reserved. 1522-2152/2010/8301-8258\$15.00 DOI: $10.1086 / 605416$

\section{Introduction}

Physiological adaptation to environmental variability allows ectotherms to maintain homeostasis and survive exposure to ensuing conditions. Ectotherms can increase temperature tolerance through behavioral exploitation of thermal environments that are available in a heterogeneous landscape and during seasonal or diel cycles (Hutchison and Maness 1979). Acclimation of thermal tolerance can occur gradually (i.e., over weeks or months), coincident with seasonal changes in ambient temperature, or relatively quickly (i.e., over hours or days), reflecting a response to more transient thermal exposure.

Among vertebrate ectotherms, acclimation of heat tolerance is generally achieved more quickly than is acclimation of cold tolerance (Hutchison and Maness 1979), although little is known about the actual time course for the latter. Many studies have documented compensatory changes in cold hardiness associated with chronic or long-term chilling of the organism, but much less attention has been paid to adjustment of physiological functions and survival limits following more acute exposure to cold. This is surprising given that many species, especially temperate ones, encounter thermal variation over the short term. A rapid cold-hardening response has been described in insects and a few other arthropods (see Lee et al. 1987), and at least one study (Layne and Claussen 1987) suggests that vertebrate ectotherms can rapidly increase their cold tolerance in response to acute temperature change. This ability, which allows cold hardiness to track diel and short-term fluctuations in ambient temperature, may be of general importance in determining the biogeographical distributions of temperate organisms (Tomanek 2008).

Whereas the mechanisms underlying seasonal enhancement of cold hardiness are reasonably well known, much less is understood about the basis of short-term enhancement (Loeschcke and Sorensen 2005; Sinclair and Roberts 2005). In the seminal article about rapid cold hardening, Lee et al. (1987) reported that improved cold hardiness was correlated with increased concentrations of the cryoprotectant glycerol, reminiscent of the seasonal accumulation of cryoprotectants exhibited by many species (Lee 1991; Layne 1999). Recently, the role of membrane-lipid responses to rapid cold hardening has garnered attention (Overgaard et al. 2005; Lee et al. 2006a; Michaud and Denlinger 2006). Structural changes to membranes presumably afford protection to cells by preventing cytosol leak and electrochemical-gradient collapse that would otherwise occur at critically low temperatures. In addition, a rapid increase in cold hardiness at the organismal level may reflect adaptive changes to all cells, or perhaps only to those particularly susceptible to 
low-temperature injury, such as neurons (Kelty et al. 1996; Collins et al. 1997; Costanzo et al. 1997, 1999).

Our goal in this study was to examine whether a vertebrate ectotherm could rapidly enhance its cold hardiness in response to relatively short-term exposure to subzero cold. We used the northerly distributed painted turtle (Chrysemys picta) as a model organism because both the limits of cold hardiness and the winter thermal environment of this species are fairly well known (see review by Costanzo et al. 2008). Painted turtles hatch in late summer but usually remain in their subterranean nest until spring (Gibbons and Nelson 1978). As winter approaches and nest temperatures fall, hatchlings become more cold hardy and are able to survive modest subzero exposures either by freezing or by remaining supercooled (Costanzo et al. 1998). However, nest temperatures in winter can fluctuate substantially, including abrupt decreases (i.e., $0^{\circ}$ to $-13^{\circ} \mathrm{C}$ in 24 h; Packard et al. 1997), and in the northern part of the painted turtle's range can be less than $-15^{\circ} \mathrm{C}$ (Costanzo et al. 2008). Having the capacity to rapidly enhance cold hardiness during the more extreme temperature fluctuations would seemingly lessen winter mortality.

We tested the hypothesis that these turtles exhibit increased cold hardiness following a brief exposure to moderate chilling, herein termed cold conditioning, by testing them for an improvement in supercooling capacity, inoculation resistance, freeze tolerance, and chill tolerance (i.e., survival in the supercooled state). Further, we investigated potential mechanisms underlying the putative increase in cold hardiness by way of cold conditioning by measuring changes in cryoprotectant concentrations and direct and indirect effects on cell survival.

\section{Material and Methods}

\section{Acquisition of Turtles and Winter Acclimation}

Eggs of the western painted turtle (Chrysemys picta bellii) were harvested from oxytocin-treated females (Ewert and Legler 1978) collected from areas surrounding Crescent Lake National Wildlife Refuge, Garden County, Nebraska. Eggs were placed on moist vermiculite ( $1 \mathrm{~g}$ water : $1 \mathrm{~g}$ dry vermiculite) and delivered to Miami University where they were incubated at $28.5^{\circ} \mathrm{C}$ until hatching. Eggshells were discarded and neonates were transferred to fresh vermiculite $(0.5 \mathrm{~g}$ water : $1 \mathrm{~g}$ dry vermiculite) and held at $20^{\circ} \mathrm{C}$ in a darkened incubator (Percival I-35X, Boone, IA). Turtles were winter acclimated by exposing them to stepwise decreases in temperatures, approximating those experienced in natural C. picta nests (Costanzo et al. 2000). Incubator temperature was decreased to $15^{\circ}, 10^{\circ}$, and $4^{\circ} \mathrm{C}$ on the first day of October, November, and December, respectively. Turtles were kept at $4^{\circ} \mathrm{C}$ for at least $3 \mathrm{wk}$ before use in experiments.

\section{Cold-Conditioning Protocol}

Turtles destined to be cold conditioned were brushed clean of any adherent vermiculite and held overnight in an empty cup at $4^{\circ} \mathrm{C}$ to allow evaporation of surface moisture. Next, they were placed individually inside clean, dry, 50-mL centrifuge tubes. A 26-gauge thermocouple was lowered into each tube and positioned such that the measuring junction rested against the turtle's plastron, and the tube's opening was then plugged with a piece of plastic foam. During cooling, temperatures were recorded at 30-s intervals on a chart recorder (Omega 180A12, Stamford, CT).

Cold conditioning was accomplished by placing the tubes inside a programmable incubator (Percival I-35X) and cooling the turtles in a linear fashion, from $-1^{\circ}$ to $-7^{\circ} \mathrm{C}\left(-0.08^{\circ} \mathrm{C}\right.$ $\mathrm{h}^{-1}$ ), over a period of $3 \mathrm{~d}$. Turtles were held at the target temperature, $-7^{\circ} \mathrm{C}$, for $2 \mathrm{~d}$ before being transferred to an ice bath $\left(\sim 0^{\circ} \mathrm{C}\right)$, where they remained for $1 \mathrm{~h}$ before being used in experiments or physiological assays. Turtles destined to serve as controls were treated similarly, except that they were held at $4^{\circ} \mathrm{C}$ for $5 \mathrm{~d}$, rather than being cooled to $-7^{\circ} \mathrm{C}$.

\section{Tests of Cold Hardiness}

Supercooling capacity is a measure of an organism's ability to remain unfrozen when cooled in the absence of exogenous ice and ice-nucleating agents (INAs), substances that can seed ice crystal formation within body fluids. Following Costanzo et al. (2003), we assessed the supercooling limit of control $(n=6)$ and cold-conditioned $(n=10)$ turtles by progressively cooling them until they spontaneously froze. Turtles, still in clean, dry, $50-\mathrm{mL}$ tubes, were suspended in a refrigerated ethanol bath (Neslab RTE 140, Portsmouth, $\mathrm{NH}$ ) initially set at $0.0^{\circ} \mathrm{C}$ and cooled to $-20.0^{\circ} \mathrm{C}$ in a linear fashion at $-1.0^{\circ} \mathrm{C} \mathrm{h}^{-1}$. The temperature of crystallization $\left(T_{\mathrm{c}}\right)$, defined as the lowest temperature recorded immediately preceding appearance of the freezing exotherm, was determined for each turtle.

Inoculation resistance refers to an organism's ability to remain unfrozen when cooled in contact with ice and INAs that may naturally occur in its microenvironment. Following Costanzo et al. (1998), we assessed inoculation resistance of control $(n=15)$ and cold-conditioned $(n=15)$ turtles by progressively cooling individuals surrounded by frozen soil and determining their $T_{\mathrm{c}}$. Turtles were immersed in $12 \mathrm{~g}$ of hydrated $(5 \% \mathrm{w} / \mathrm{w})$ sandy soil collected from the nesting area within a $50-\mathrm{mL}$ tube. Tubes were then suspended in a refrigerated ethanol bath and held at $-0.4^{\circ} \mathrm{C}$ to freeze the soil solution; freezing was initiated by adding a few ice chips. Because the turtle's body fluid has an equilibrium freezing point of about $-0.6^{\circ} \mathrm{C}$ (Costanzo et al. 2008), the soil froze without freezing the turtle. After the soil had reached an equilibrium ice content, evidenced by the completion of its freezing exotherm, the bath was cooled to $-12.0^{\circ} \mathrm{C}$ at a uniform rate of $-1.0^{\circ} \mathrm{C} \mathrm{h}^{-1}$, causing the turtles to ultimately freeze.

Natural freeze tolerance refers to an organism's ability to survive somatic freezing under ecologically relevant thermal and temporal conditions. We assessed the capacity for freeze tolerance of control $(n=15)$ and cold-conditioned $(n=14)$ turtles by monitoring their recovery from being held frozen for $\sim 70$ h. Turtles, still in clean, dry, 50-mL tubes, were suspended in a refrigerated ethanol bath set at $-1.2^{\circ} \mathrm{C}$. We induced turtles 
to freeze by placing ice chips in contact with their axillary skin after they had cooled to about $-0.6^{\circ} \mathrm{C}$, the tissue's equilibrium freezing point. We maintained the bath at $-1.2^{\circ} \mathrm{C}$ until the freezing turtles attained thermoequilibrium, which took $\sim 1.5$ $\mathrm{h}$. Bath temperature was then reduced in a linear fashion at $-0.07^{\circ} \mathrm{C} \mathrm{h}^{-1}$ to $-3.75^{\circ} \mathrm{C}$ where it remained for $24 \mathrm{~h}$. Turtles were then warmed $\left(0.3^{\circ} \mathrm{C} \mathrm{h}^{-1}\right)$ to $-1.0^{\circ} \mathrm{C}$, and their tubes were transferred to an ice bath $\left(\sim 0^{\circ} \mathrm{C}\right)$ where they were held for 1 h. Turtles were placed on moist paper towels in individual plastic cups and held in darkness at $4^{\circ} \mathrm{C}$. Following Costanzo et al. (2006), each turtle was tested for viability daily by gently prodding its limbs with a blunt probe. A turtle was considered to be alive if during an 11-d recovery period it retracted at least one of its limbs in response to the tactile stimulus.

Chill tolerance refers to an organism's ability to survive a low-temperature exposure in the absence of somatic freezing. We assessed the capacity for chill tolerance of control $(n=$ $20)$ and cold-conditioned $(n=20)$ turtles by holding them in the supercooled state at $-13^{\circ} \mathrm{C}$ for $24 \mathrm{~h}$ and monitoring their recovery following rewarming. Turtles were transferred in their clean, dry, 50-mL tubes to a programmable incubator (Percival I-35X) initially set at $-1^{\circ} \mathrm{C}$. After reaching thermoequilibrium, turtles were chilled in a linear fashion at $-1^{\circ} \mathrm{C} \mathrm{h}^{-1}$ to $-13^{\circ} \mathrm{C}$, held at this temperature for $24 \mathrm{~h}$, and then warmed $\left(1^{\circ} \mathrm{C} \mathrm{h}^{-1}\right)$ to $-1^{\circ} \mathrm{C}$. Next, their tubes were transferred to an ice bath $\left(\sim 0^{\circ} \mathrm{C}\right)$ where they were held for $1 \mathrm{~h}$. Whereas the viability of most of these cold-shocked turtles was evaluated (as above) over a 7-d recovery period, a subset was used for assays of brain-cell viability (see below).

\section{Blood and Tissue Analyses}

Tissues of some turtles were examined to determine the effects of cold conditioning on the concentrations of certain osmolytes as well as responses to cold shock at the cellular level. Turtles were killed by decapitation, and blood was drawn into heparinized microhematocrit tubes from severed vessels in the neck and, when necessary, from the heart after quick removal of the plastron. Whole blood was immediately centrifuged $(4,000 \mathrm{~g}$, $5 \mathrm{~min}$ ), and the plasma was collected and stored at $-80^{\circ} \mathrm{C}$. Samples of plasma were later thawed on ice and assayed for osmolality and the putative cryoprotectants glucose, lactate, and urea. Osmolality was measured in $10-\mu \mathrm{L}$ aliquots on a Wescor vapor-pressure osmometer (model 5500; Logan, UT) calibrated with $\mathrm{NaCl}$ standards; enzymatic procedures were used to determine plasma concentrations of glucose (glucose oxidase, Sigma no. 510, St. Louis, MO), lactate (lactate dehydrogenase, Sigma no. 735), and urea (urease, Pointe Scientific no. B7551120, Canton, MI).

In some samples of plasma, we measured activity of lactate dehydrogenase ( $\mathrm{LDH})$, a cytosolic enzyme whose leakage into the general circulation indicates damage to plasma membranes. LDH activity was measured (Sigma no. TOX-7) in plasma of control $(n=5)$ and cold-conditioned $(n=8)$ turtles to determine whether cold conditioning was injurious. It was also measured in cold-shocked turtles (control, $n=10$; coldconditioned, $n=9$ ) following the 7 -d recovery period to shed light on the mechanism of chilling injury.

Viability of brain cells from cold-shocked turtles, and from additional (untreated) turtles taken directly from cages at $4^{\circ} \mathrm{C}$, was assessed using a cell-viability stain (Molecular Probes no. L-7011, Eugene, OR) containing the green, membranepermeable dye SYBR and the red, membrane-impermeable dye propidium iodide as modified by Yi and Lee (2003). Coldshocked turtles were sampled immediately after rewarming to $0^{\circ} \mathrm{C}$; thus, the level of injury manifested in cells was directly associated with the cold-shock treatment, rather than secondary degradation. Five turtles from each group were killed by decapitation and a $\sim 1-\mathrm{mg}$ section of the dorsal cerebrum was excised. The tissue was placed on a microscope slide containing $25 \mu \mathrm{L}$ of $0.02 \mathrm{mmol} \mathrm{L}^{-1}$ SYBR in phosphate-free buffer $(100$ mmol L ${ }^{-1}$ HEPES, $150 \mathrm{mmol} \mathrm{L}^{-1} \mathrm{NaCl}$ ) and incubated $15 \mathrm{~min}$ at $\sim 22^{\circ} \mathrm{C}$ in the dark. Then, $25 \mu \mathrm{L}$ of $0.10 \mathrm{mmol} \mathrm{L}^{-1}$ propidium iodide in phosphate-free buffer was added to the slide. After a second 15-min incubation, a coverslip was applied and the tissue was viewed under WBV light using fluorescent microscopy (Olympus BH-2, Tokyo). Cells with intact membranes fluoresced green and were considered alive, whereas cells with permeabilized membranes fluoresced red or orange and were considered dead. For each tissue sample, we determined the viability of all cells (median count $=284$ cells) within a $10 \times$ field of view near the margin, where the tissue was sufficiently thin to discern separate cells. Data were pooled among samples within each group. All experimental procedures were approved by the Institutional Animal Care and Use Committee of Miami University (protocol 645).

\section{Statistical Analyses}

Statistical analyses were performed using SAS 9.1, and significance was accepted at $P \leq 0.05$. Mean values are presented $\pm \mathrm{SE}$ and were compared between groups using Student's $t$-test or a one-way ANOVA after confirming that data sets met assumptions of parametric tests. Proportions were compared between groups using Fisher's exact test or $\chi^{2}$ test.

\section{Results}

\section{Effect of Cold Conditioning on Supercooling Limit and} Inoculation Resistance

Turtles cooled in the absence of external ice and INAs remained supercooled until spontaneously freezing at temperatures well below the equilibrium freezing point. Cold conditioning did not affect the supercooling capacity of turtles, as the mean $T_{c}$ of cold-conditioned individuals $\left(-17.3^{\circ} \pm 0.3^{\circ} \mathrm{C}\right.$; range $-15.6^{\circ}$ to $\left.-19.0^{\circ} \mathrm{C} ; n=10\right)$ did not significantly $\left(t_{14}=0.39, P=\right.$ $0.703)$ differ from that of controls $\left(-17.5^{\circ} \pm 0.4^{\circ} \mathrm{C}\right.$; range $-15.7^{\circ}$ to $-18.5^{\circ} \mathrm{C} ; n=6$ ).

In contrast, turtles immersed in frozen soil and cooled in 
intimate contact with external ice and INAs spontaneously froze at temperatures only slightly below the equilibrium freezing point. Similar to the outcome of the supercooling-capacity trials, the mean $T_{\mathrm{c}}$ of cold-conditioned turtles $\left(-2.2^{\circ} \pm 0.3^{\circ} \mathrm{C}\right.$; range $-0.9^{\circ}$ to $\left.-5.2^{\circ} \mathrm{C} ; n=15\right)$ was not significantly $\left(t_{28}=\right.$ 1.98, $P=0.058)$ different from that of controls $\left(-3.5^{\circ} \pm\right.$ $0.6^{\circ} \mathrm{C}$; range $-0.9^{\circ}$ to $-9.6^{\circ} \mathrm{C} ; n=15$ ).

\section{Effect of Cold Conditioning on Freeze Tolerance}

No turtle from the freeze-tolerance trials showed signs of recovery immediately after thawing, although about one quarter $(n=7)$ of them ultimately met our survival criterion. By the end of the 11-d postthaw period of recovery, a nominally higher percentage $(36 \%)$ of cold-conditioned individuals had met our survival criterion compared with controls (13\%), but the difference was not statistically significant (Fisher's exact test, $P=0.135$; Fig. 1). However, survivors from the cold-conditioned group recovered more quickly than those from the control group (Fig. 2) and responded to prodding with all limbs, whereas those from the control group responded with only one or two limbs, suggesting that the former had a more robust recovery.

\section{Effect of Cold Conditioning on Chill Tolerance}

Cold-shocked turtles remained unfrozen throughout the chilling exposure, evidenced by a lack of freezing exotherms in the temperature recordings. No turtle from these trials showed signs of viability immediately after rewarming, as was the case with turtles used in the freeze-tolerance trials. However, compared with specimens in the freeze-tolerance trials, coldshocked turtles recovered more quickly, within 1-2 d. By the

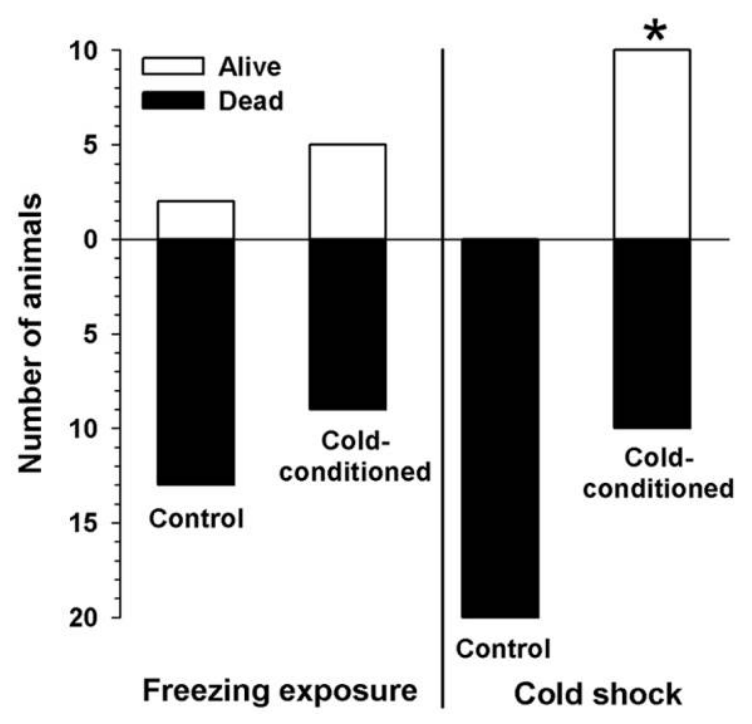

Figure 1. Viability status of control and cold-conditioned turtles after their respective periods of recovery from experimental freezing or cold shock. An asterisk denotes a significant $(P<0.05)$ difference between control and cold-conditioned turtles.

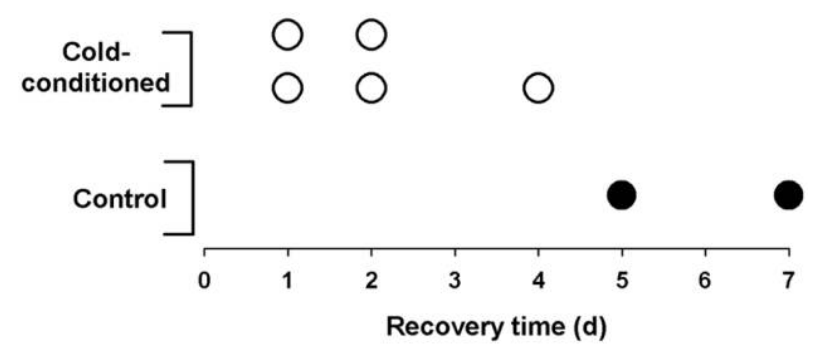

Figure 2. Recovery times of individual control (filled circles) and coldconditioned (open circles) turtles subjected to experimental freezing.

end of the 7-d recovery period, none of the controls met our survival criterion, but half of the cold-conditioned turtles had recovered (Fisher's exact test, $P=0.0002$; Fig. 1).

\section{Mechanisms of Enhanced Cold Hardiness through Cold Conditioning}

Turtles $(n=8)$ subjected to cold conditioning responded to tactile stimulation of their limbs immediately after rewarming. Analysis of their blood showed that levels of glucose and lactate, but not urea, were significantly higher compared with those of controls $(n=5)$. Accordingly, their plasma osmolality was also higher (Table 1). Measuring the activity of LDH in blood plasma served to index the level of plasma-membrane injury. Cold conditioning had no effect on this metric, as the mean value for cold-conditioned turtles $\left(2.3 \pm 0.6 \mathrm{IU} \mathrm{mL} \mathrm{mL}^{-1} ; n=8\right)$ did not differ $\left(t_{11}=0.87, P=0.404\right)$ from that $(1.3 \pm 0.9 \mathrm{IU}$ $\left.\mathrm{mL}^{-1} ; n=5\right)$ of controls.

Among the cold-shocked turtles, cold conditioning apparently had little effect on cellular leakage of LDH during the 7$\mathrm{d}$ recovery period, as plasma activity levels of this enzyme were similar between cold-conditioned and control turtles (Fig. 3A). However, these levels were also similar $\left(F_{2,21}=2.90, P=\right.$ 0.077 ) to those measured in untreated turtles taken directly from cages at $4^{\circ} \mathrm{C}$; thus; the cold-shock treatment was not a substantial cause of protein leakage. In contrast, cold shock resulted in a level of mortality of brain cells that was higher $\left(\chi^{2}=168.14, P<0.0001\right)$ than that measured in untreated turtles, although the adverse effect was ameliorated $\left(\chi^{2}=1.61\right.$, $P=0.205$ ) by cold conditioning (Fig. $3 B$ ).

\section{Discussion}

Ectothermic animals living in temperate climes rely on seasonal development of cold hardiness to survive wintry conditions, but for animals in habitats where large temperature fluctuations occur, more rapid increases in cold hardiness may be necessary. We have shown here that exposure to a moderate, subzero temperature over an ecologically relevant timescale enhances cold hardiness in hatchling Chrysemys picta. We suspect that such a rapid response may occur in other vertebrate ectotherms as well, especially those that naturally experience large fluctuations in body temperature over relatively short periods. 
Table 1: Concentrations of glucose, lactate, and urea ( $\mathrm{mmol}$ $\mathrm{L}^{-1}$ ) and osmolality (mOsm $\mathrm{kg}^{-1}$ ) of plasma from control and cold-conditioned turtles

\begin{tabular}{lccrc}
\hline & $\begin{array}{l}\text { Control } \\
(n=5)\end{array}$ & $\begin{array}{l}\text { Cold Conditioned } \\
(n=8)\end{array}$ & $t$ & $P$ \\
\hline [Glucose] & $5.6 \pm .6$ & $23.1 \pm 1.5$ & 8.83 & $<.0001$ \\
[Lactate] & $1.7 \pm .3$ & $7.2 \pm .6$ & 6.58 & $<.0001$ \\
[Urea] & $44.7 \pm 4.2$ & $51.1 \pm 5.5$ & .83 & .425 \\
Osmolality & $353 \pm 5$ & $383 \pm 8$ & 2.72 & .020 \\
\hline
\end{tabular}

Note. Values are mean \pm SE. Means in the same row were compared using Student's $t$-test.

\section{Cold-Hardiness Responses to Cold Conditioning}

In our experiments, neither supercooling capacity nor inoculation resistance was altered by brief cold conditioning. Seasonal enhancement of supercooling capacity in hatchling C. picta is facilitated by attenuation or masking of endogenous INAs, as well as elimination of ingested INAs from the gut (Costanzo et al. 2003). Judging from their extensive supercooling capacity, our winter-acclimated turtles had already undergone these processes and perhaps were unable to further enhance their supercooling capacity. Enhancement of inoculation resistance in C. picta apparently involves morphological and ultrastructural changes to the integument and generally occurs in preparation for winter (Costanzo et al. 2008). Our data suggest that cold conditioning of winter-acclimated turtles had no effect on inoculation resistance, implying further changes to the integument did not occur.

Although cold conditioning clearly did not affect freeze avoidance in hatchling C. picta, its effect on freeze tolerance was more equivocal. The proportion of cold-conditioned turtles that survived in freeze-tolerance trials was nominally (although not statistically) higher than that of controls. Given that the lower thermal limit of freeze tolerance in hatchling C. picta is $-3^{\circ}$ to $-4^{\circ} \mathrm{C}$ (Costanzo et al. 2008), the high mortality in both groups of turtles exposed to $-3.75^{\circ} \mathrm{C}$ was not unexpected. However, using a less severe exposure possibly would have allowed us to better distinguish rates of survival between coldconditioned and control turtles. Nevertheless, that surviving cold-conditioned turtles recovered more robustly and more quickly (Fig. 2) than did surviving controls suggests that capacity for freeze tolerance may be modulated by short-term variation in environmental temperature. Additional research is needed to determine whether cold conditioning affects animal freeze tolerance. Whereas many studies of invertebrates have shown rapid increases in chill tolerance after cold conditioning, only one previous study (Lee et al. 2006b) has documented a swift enhancement of freezing survival.

\section{Suborganismal Cryoinjury}

To better understand the underlying causes of the increased cold hardiness of turtles, we examined the effects of cold con- ditioning at the physiological and cellular levels of organization. Cryoinjury at the cellular level, whether from freezing or extensive supercooling, is thought to involve damage to phospholipid membranes (Caffrey 1987; Kostal et al. 2004). Low temperature can damage membranes directly by inducing a phase transition of phospholipid bilayers from a liquidcrystalline to a gel state, thereby compromising membrane function (Drobnis et al. 1993) and allowing cytosolic components to leak out of the cell. However, our assessment of LDH activity in blood plasma suggests that cold shock did not result in widespread damage to cell membranes (Fig. $3 A$ ), even in turtles that did not survive. In contrast, freeze/thaw stress, which is known to perturb membranes, induces LDH leakage in hatchling C. picta (Costanzo et al. 2006). That cold shock was lethal to control turtles, but did not cause widespread LDH leakage, could be explained by apoptotic cell death, which minimizes cytosol leakage by packaging intracellular components into vesicles. Chilling-induced apoptosis is a key obstacle facing successful hypothermic storage of mammalian tissues (Baust 2007) and can be attenuated by rapid cold hardening in Drosophila melanogaster (Yi et al. 2007). However, lethal chilling could also occur without extensive leakage of $\mathrm{LDH}$ if only a

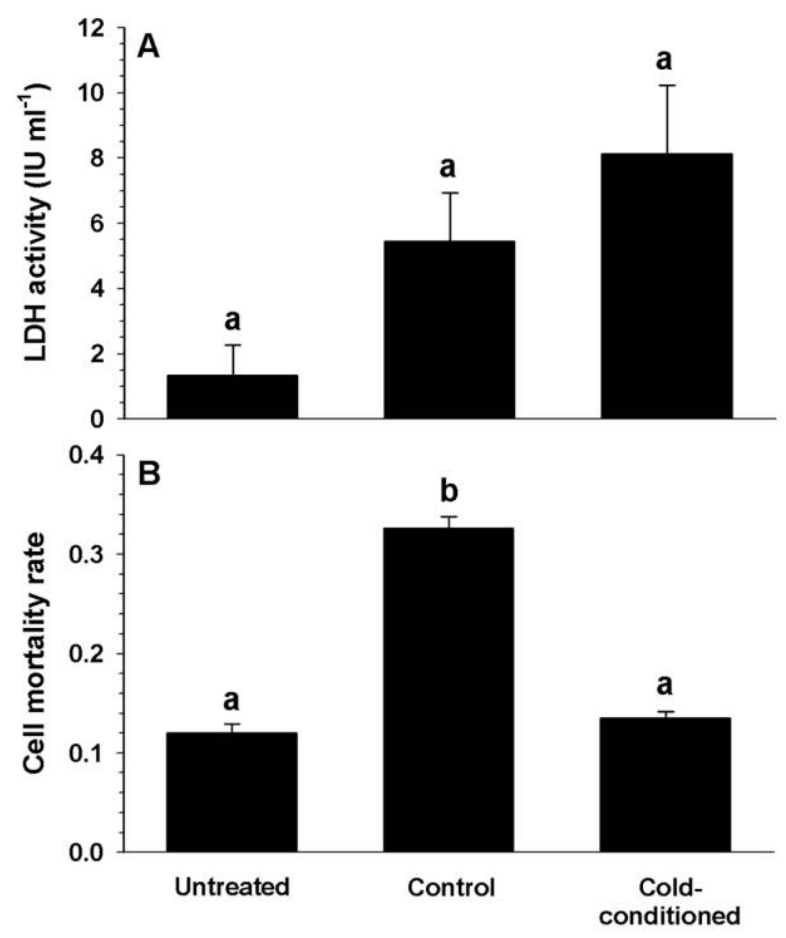

Figure 3. Markers of cryoinjury from cold shock. $A$, Mean \pm SE activity of lactate dehydrogenase $(L D H)$ in blood plasma from untreated turtles $(n=5)$ taken directly from cages at $4^{\circ} \mathrm{C}$, and control $(n=10)$ and cold-conditioned $(n=9)$ turtles given a cold shock (ANOVA; $\left.F_{2,21}=2.90, P=0.077\right)$. $B$, Proportion $\pm \mathrm{SE}$ of dead cells from brains of untreated turtles taken directly from cages at $4^{\circ} \mathrm{C}$, and control and cold-conditioned turtles given a cold shock (three-sample $\chi^{2}$ test; $\chi^{2}=279.42, P<0.0001$; post hoc two-sample $\chi^{2}$ tests with a Bonferroni $\alpha$-adjustment). Columns not sharing a common letter are significantly different $(P<0.017)$. 
few particularly sensitive cell types, such as those in nervous tissue, were injured. The nervous system appears especially susceptible to cryoinjury based on studies of behavior (Friedlander et al. 1976; Costanzo et al. 1999), neuromuscular function (Li and Gouras 1958; Kelty et al. 1996; Kostal et al. 2004), and histology (Collins et al. 1997). Indeed, examining brain tissue collected from cold-shocked control turtles immediately after rewarming indicated that cells had sustained substantial damage directly due to cold exposure. Elimination of this damage in cold-conditioned turtles (Fig. $3 B$ ) corresponded with increased survival at the whole-animal level in chill-tolerance trials (Fig. 1 ), suggesting a link between protection of the nervous system and recovery at the organismal level. However, our data are correlative, and thus we cannot distinguish cause and effect with respect to the relationship between mortality of brain cells and that of the turtle.

Possible Mechanisms of Rapid Enhancement of Cold Hardiness by Cold Conditioning

Cryoinjury is generally reduced by the presence of low-molecular-mass cryoprotectants (Acker 2007), which colligatively depress the equilibrium freezing point of body fluids and may protect cells noncolligatively by interacting with plasma membranes or stabilizing macromolecules. As commonly occurs during supercooling (Costanzo et al. 2008), plasma levels of the putative cryoprotectants glucose and lactate were increased in hatchling $C$. picta by cold conditioning, but the concentrations were probably too low to confer protection against cryoinjury by way of colligative effects. Intracellular glucose provides an important source of glycolytic fuel during the ischemic hypoxia that accompanies somatic freezing and deep supercooling, but our turtles were kept under these conditions for a relatively short time, making it unlikely that the beneficial effect of cold conditioning was due to higher levels of glycolytic substrate. Whether such low levels of glucose and lactate can cryoprotect membranes and macromolecules remains to be determined; however, a slight increase in glucose was correlated with protection from cold-shock injury in D. melanogaster (Overgaard et al. 2007). Urea potentially can prevent cryoinjury in hatchling turtles (Costanzo et al. 2008), but our specimens apparently did not accumulate this osmolyte during cold conditioning. The difference in plasma osmolality between cold-conditioned and control turtles, $30 \mathrm{mOsm} \mathrm{kg}^{-1}$, was fully accounted for by a corresponding difference in the sums of the measured amounts of glucose, lactate, and urea; thus, no other major osmolyte was accumulated during cold conditioning.

Preservation of macromolecular function at low temperatures is an essential component of an organism's cold hardiness. Transient cold exposure followed by return to higher temperatures can induce expression of heat shock proteins (HSPs; Joplin et al. 1990; Sejerkilde et al. 2003), which possibly could increase both freeze tolerance and chill tolerance in hatchling C. picta by ameliorating cytoskeletal perturbation (Klose and Robertson 2004; Robertson 2004) or by inhibiting apoptosis
(Schlesinger et al. 1990). Moreover, HSPs reportedly assist in the repair of chilling injury (Kostal and Tollarova-Borovanska 2009) and thus may facilitate recovery from low-temperature damage. A fundamental mechanism of cryoinjury is thought to be the loss of plasma membrane integrity (Drobnis et al. 1993). Among invertebrates, reorganization of lipid bilayers takes place during both seasonal cold acclimation (Tooke and Holland 1985; Bennett et al. 1997) and rapid cold hardening (Michaud and Denlinger 2006; Overgaard et al. 2006), thereby allowing membranes to remain fluid at low temperatures (Lee et al. 2006a). It is yet unclear whether this phenomenon, termed homeoviscous adaptation, occurs in vertebrates during shortterm cold exposure, but it may underlie the protection afforded hatchling $C$. picta by cold conditioning. Further investigation into the physiological changes that occur during cold conditioning is necessary to determine the mechanistic basis of the rapid increase in cold hardiness. Understanding the processes involved in this response would not only help identify the proximal causes of low-temperature injury but would also lead to advances in cryomedicine and organ preservation.

\section{Acknowledgments}

We thank S. Dinkelacker, S. Pasachnik, and D. Green for aid in egg collections and R. Schaefer for statistical consultation. Two anonymous reviewers provided constructive suggestions for improving the manuscript. This work was supported by the Miami University Summer Field-Research Workshop and the National Science Foundation grant IAB0416750 to J.P.C.

\section{Literature Cited}

Acker J.P. 2007. The use of intracellular protectants in cell biopreservation. Pp. 299-320 in J.G. Baust and J.M. Baust, eds. Advances in Biopreservation. CRC, New York.

Baust J.M. 2007. Properties of cells and tissues influencing preservation outcome: molecular basis of preservation-induced cell death. Pp. 63-87 in J.G. Baust and J.M. Baust, eds. Advances in Biopreservation. CRC, New York.

Bennett V.A., N.L. Pruitt, and R.E. Lee. 1997. Seasonal changes in fatty acid composition associated with cold-hardening in third instar larvae of Eurosta solidaginis. J Comp Physiol B 167:249-255.

Caffrey M. 1987. The combined and separate effects of low temperature and freezing on membrane lipid mesomorphic phase behavior: relevance to cryobiology. Biochim Biophys Acta 896:123-127.

Collins S.D., A.L. Allenspach, and R.E. Lee. 1997. Ultrastructural effects of lethal freezing on brain, muscle and malpighian tubules from freeze-tolerant larvae of the gall fly, Eurosta solidaginis. J Insect Physiol 43:39-45.

Costanzo J.P., P.J. Baker, S.A. Dinkelacker, and R.E. Lee. 2003. Endogenous and exogenous ice-nucleating agents constrain 
supercooling in the hatchling painted turtle. J Exp Biol 206: 477-485.

Costanzo J.P., P.J. Baker, and R.E. Lee. 2006. Physiological responses to freezing in hatchlings of freeze-tolerant and -intolerant turtles. J Comp Physiol B 176:697-707.

Costanzo J.P., J.T. Irwin, and R.E. Lee. 1997. Freezing impairment of male reproductive behaviors of the freeze-tolerant wood frog, Rana sylvatica. Physiol Zool 70:158-166.

Costanzo J.P., R.E. Lee, and G.R. Ultsch. 2008. Physiological ecology of overwintering in hatchling turtles. J Exp Zool 309A:297-379.

Costanzo J.P., J.D. Litzgus, J.B. Iverson, and R.E. Lee. 1998. Soil hydric characteristics and environmental ice nuclei influence supercooling capacity of hatchling painted turtles, Chrysemys picta. J Exp Biol 201:3105-3112.

- 2000. Seasonal changes in physiology and development of cold hardiness in the hatchling painted turtle, Chrysemys picta. J Exp Biol 203:3459-3470.

Costanzo J.P., J.D. Litzgus, and R.E. Lee. 1999. Behavioral responses of hatchling painted turtles (Chrysemys picta) and snapping turtles (Chelydra serpentina) at subzero temperatures. J Therm Biol 24:161-166.

Drobnis E.Z., L.M. Crowe, T. Berger, T.J. Anchordoguy, J.W. Overstreet, and J.H. Crowe. 1993. Cold shock damage is due to lipid phase transitions in cell membranes: a demonstration using sperm as a model. J Exp Zool 265:432-437.

Ewert M.A. and J.M. Legler. 1978. Hormonal induction of oviposition in turtles. Herpetologica 34:314-318.

Friedlander M.J., N. Kotchabkakdi, and C.L. Prosser. 1976. Effects of cold and heat on behavior and cerebellar function in goldfish. J Comp Physiol A 112:19-45.

Gibbons J.W. and D.H. Nelson. 1978. The evolutionary significance of delayed emergence from the nest by hatchling turtles. Evolution 32:297-303.

Hutchison V.H. and J.D. Maness. 1979. The role of behavior in temperature acclimation and tolerance in ectotherms. Am Zool 19:367-384.

Joplin K.H., G.D. Yocum, and D.L. Denlinger. 1990. Cold shock elicits expression of heat shock proteins in the flesh fly, Sarcophaga crassipalpis. J Insect Physiol 36:825-834.

Kelty J.D., K.A. Killian, and R.E. Lee. 1996. Cold shock and rapid cold-hardening of pharate adult flesh flies (Sarcophaga crassipalpis): effects on behaviour and neuromuscular function following eclosion. Physiol Entomol 21:283-288.

Klose M.K. and R.M. Robertson. 2004. Stress-induced thermoprotection of neuromuscular transmission. Integr Comp Biol 44:14-20.

Kostal V. and M. Tollarova-Borovanska. 2009. The $70 \mathrm{kDa}$ heat shock protein assists during the repair of chilling injury in the insect, Pyrrhocoris apterus. PLoS ONE 4:e4546.

Kostal V., J. Vambera, and J. Bastl. 2004. On the nature of prefreeze mortality in insects: water balance, ion homeostasis and energy charge in the adults of Pyrrhocoris apterus. J Exp Biol 207:1509-1521.

Layne J.R. 1999. Freeze tolerance and cryoprotectant mobili- zation in the gray treefrog (Hyla versicolor). J Exp Zool 283: 221-225.

Layne J.R. and D.L. Claussen. 1987. Time courses of thermal acclimation for critical thermal minima in the salamanders Desmognathus quadramaculatus, Desmognathus monticola, Desmognathus ochrophaeus, and Plethodon jordani. Comp Biochem Physiol A 87:895-898.

Lee R.E. 1991. Principles of insect low temperature tolerance. Pp. 17-46 in R.E. Lee Jr. and D.L. Denlinger, eds. Insects at Low Temperature. Chapman \& Hall, New York.

Lee R.E., C.-P. Chen, and D.L. Denlinger. 1987. A rapid coldhardening process in insects. Science 238:1415-1417.

Lee R.E., K. Damodaran, S.-X. Yi, and G.A. Lorigan. $2006 a$. Rapid cold-hardening increases membrane fluidity and cold tolerance of insect cells. Cryobiology 52:459-463.

Lee R.E., M.A. Elnitsky, J.P. Rinehart, S.A. Hayward, L.H. Sandro, and D.L. Denlinger. 2006b. Rapid cold-hardening increases the freezing tolerance of the Antarctic midge Belgica antarctica. J Exp Biol 209:399-406.

Li C.-L. and P. Gouras. 1958. Effect of cooling on neuromuscular transmission in the frog. Am J Physiol 192:464-470.

Loeschcke V. and J.G. Sorensen. 2005. Acclimation, heat shock and hardening - a response from evolutionary biology. J Therm Biol 30:255-257.

Michaud M.R. and D.L. Denlinger. 2006. Oleic acid is elevated in cell membranes during rapid cold-hardening and pupal diapause in the flesh fly, Sarcophaga crassipalpis. J Insect Physiol 52:1073-1082.

Overgaard J., A. Malmendal, J.G. Sorensen, J.G. Bundy, V. Loeschcke, N.C. Nielsen, and M. Holmstrup. 2007. Metabolomic profiling of rapid cold hardening and cold shock in Drosophila melanogaster. J Insect Physiol 53:1218-1232.

Overgaard J., J.G. Sorensen, S.O. Petersen, V. Loeschcke, and M. Holmstrup. 2005. Changes in membrane lipid composition following rapid cold hardening in Drosophila melanogaster. J Insect Physiol 51:1173-1182.

- 2006. Reorganization of membrane lipids during fast and slow cold hardening in Drosophila melanogaster. Physiol Entomol 31:328-335.

Packard G.C., S.L. Fasano, M.B. Attaway, L.D. Lohmiller, and T.L. Lynch. 1997. Thermal environment for overwintering hatchlings of the painted turtle (Chrysemys picta). Can J Zool 75:401-406.

Robertson R.M. 2004. Modulation of neural circuit operation by prior environmental stress. Integr Comp Biol 44:21-27.

Schlesinger M.J., M.G. Santoro, and E. Garaci. 1990. Stress Proteins: Induction and Function. Springer, New York.

Sejerkilde M., J.G. Sorensen, and V. Loeschcke. 2003. Effects of cold- and heat hardening on thermal resistance in Drosophila melanogaster. J Insect Physiol 49:719-726.

Sinclair B.J. and S.P. Roberts. 2005. Acclimation, shock, and hardening in the cold. J Therm Biol 30:557-562.

Tomanek L. 2008. The importance of physiological limits in determining biogeographical range shifts due to global climate change: the heat-shock response. Physiol Biochem Zool 81:709-717. 
Tooke N.E. and D.L. Holland. 1985. Phospholipid fatty acid composition and cold tolerance in two species of barnacle, Balanus balanoides and Elminius modestus. I. Summer versus winter variations in phospholipid fatty acid composition of whole animals. J Exp Mar Biol Ecol 87:241-253.

Yi S.-X. and R.E. Lee. 2003. Detecting freeze injury and seasonal cold-hardening of cells and tissues in the gall fly larvae, $\mathrm{Eu}$ rosta solidaginis (Diptera: Tephritidae) using fluorescent vital dyes. J Insect Physiol 49:999-1004.

Yi S.-X., C.W. Moore, and R.E. Lee. 2007. Rapid cold-hardening protects Drosophila melanogaster from cold-induced apoptosis. Apoptosis 12:1183-1193. 